\title{
Fate of dissolved organic matter in deep sea hydrothermal fluids
}

Gabriel Dulaquais ${ }^{1 *}$, Pierre Fourrier ${ }^{1}$, Agathe Laës ${ }^{2}$, Pierre-Marie Sarradin ${ }^{3}$, Géraldine Sarthou ${ }^{1}$, Matthieu Waeles ${ }^{1}$, and Ricardo Riso ${ }^{1}$

${ }^{1}$ Laboratoire des Sciences de l'Environnement Marin UMR 6539 CNRS/ Ifremer/UBO/IRD, Institut Universitaire Européen de la Mer. Place Nicolas Copernic - 29280 Plouzané, France.

${ }^{2}$ Laboratoire Détection Capteur et Mesure, Ifremer centre Bretagne - ZI de la Pointe du Diable - CS 10070 - 29280 Plouzané, France

${ }^{3}$ Laboratoire Environnement Profond, Ifremer centre Bretagne - ZI de la Pointe du Diable - CS 10070 - 29280 Plouzané, France

* Corresponding author : Gabriel.dulaquais@univ-brest.fr

We present new results on the distribution and composition of dissolved organic matter (DOM) in deep sea hydrothermal fluids. Samples collected at the Lucky Strike deep sea hydrothermal vent field ( $>1500 \mathrm{~m}$, Mid Atlantic Ridge) cover the hydrothermal gradient from the very first stage of mixing to the diluted part of the plume. Samples were filtered in situ to prevent DOM adsorption onto particles after sampling.

Capelinhos vent site was found to be a source of dissolved organic carbon (DOC). At this site, DOM of the hydrothermal fluid significantly differed from the marine end-member. It was mostly composed of small $(<300 \mathrm{Da})$ and uncharged molecules with a significant part of aromatic carbon. Furthermore, we found that this vent fluid was a sink for humic-like substances (HS). Our results suggest a full thermal degradation of humic substances at a temperature around $200^{\circ} \mathrm{C}$ with changes in the composition and molecular weight during this process. A deficit of HS to the theoretical mixing line was also observed. This deficit occurred between 80 and $8^{\circ} \mathrm{C}$ when the $\mathrm{pH}$ significantly increased from 5.3 to 6.3 . We relate this deficit to the adsorption of HS onto iron (Fe) oxyhydroxides. Fe oxy-hydroxide formation just starts in this domain and has been shown to be limited. Nevertheless, considering ambient dissolved Fe concentrations $(>100 \mu \mathrm{M})$, even a small Fe precipitation rate can produce a large amount of oxy-hydroxides. Laboratory experiments were conducted to confirm the latter hypothesis. Because deep sea HS can be considered as refractory organic matter, the adsorption of HS onto Fe minerals and its burial into deep sea sediments can be considered as a sink of oceanic carbon.

Preliminary results from distal fluid dispersion of shallow hydrothermal sources in the Western Tropical South Pacific Ocean acquired during the TONGA expedition will also be presented to further exemplify the role, at a larger scale, of hydrothermal fluid on oceanic DOM biogeochemistry. 